\title{
LUT
}

University

\section{Stimulating organisational creativity with theatrical improvisation}

Nisula Anna-Maija, Kianto Aino

This is a Final draft version of a publication

published by Elsevier

in Journal of Business Research

DOI: $10.1016 /$ j.jbusres.2017.10.027

Copyright of the original publication: (c) 2017 Elsevier Inc

Please cite the publication as follows:

Nisula, A.-M., Kianto, A. (2018). Stimulating organisational creativity with theatrical improvisation. Journal of Business Research, vol. 85. pp. 484-493. DOI: 10.1016/j.jbusres.2017.10.027

This is a parallel published version of an original publication.

This version can differ from the original published article. 


\title{
Stimulating organisational creativity with theatrical improvisation
}

\author{
Anna-Maija Nisula *) \\ Post-doctoral researcher \\ Aino Kianto \\ Professor \\ Lappeenranta University of Technology, \\ LUT School of Business and Management \\ P.O. Box 20, \\ FI-53851 Lappeenranta, Finland \\ *)Corresponding author
}

Nisula, A. M., \& Kianto, A. (2018). Stimulating organisational creativity with theatrical improvisation. Journal of Business Research, 85, 484-493.

\begin{abstract}
Although organisational creativity has become an increasingly important performance driver, little is known about how it can be built and stimulated. The existing literature has mostly focused on techniques for improving idea generation in specific and occasional problem-solving situations. However, there is scarce research about how to improve creativity as a quality that pervades everyday operations throughout an organisation. This study explores how theatrical improvisation could foster organisational creativity. Qualitative action research shows theatrical improvisation as a promising method to stimulate both individual and collective creativity in an organisation. The study links theatrical improvisation to organisational creativity, understanding the former as a potential method for organisational development. This research extends the understanding about enhancing organisational creativity as a multilevel phenomenon, as well as the possibilities for applying arts-based methods to organisational development.
\end{abstract}

Keywords Creativity, collective creativity, organisational creativity, Improvisation, Theatrical improvisation, Arts-based methods 


\section{Introduction}

In today's fast-moving digitalised economy, organisational success increasingly depends on organisational creativity (OC) - an organisation's capacity to empower its human resources towards creative action, leading to novel solutions and thereby to a sustainable competitive advantage (Styhre \& Sundgren, 2005; Zhou \& Hoever, 2014). The demand for creativity is expanding from occasional, clearly delineated problem-solving situations to an essential necessity of everyday work life and an organisation's overall capacity to stimulate its employees' potentials, enabling novel and flexible ways to achieve organisational goals.

High-performing, forward-thinking companies acknowledge that the complexity and the dynamism of current economic conditions demand an active involvement of employees' perspectives in organisational activities. Pixar is famous for nurturing collective creativity (CC) by enabling all its employees to contribute to the creative process while producing breakthrough movies. Google invests heavily in fostering a workplace culture of creativity through versatile means, from technological platforms and frequent social events to physical spaces that are intentionally built to stimulate creativity. Virgin is renowned for its culture of innovation, where employees are involved in creative activities and encouraged to produce ideas that can lead to continuous organisational development.

Also defined as an organisation's capacity to introduce novelty into what it does and how it does it in order to achieve its goals, OC is based on individual and collective behaviours of organisational members. As a collective process (Hargadon \& Bechky, 2006; Harvey 2014; Harvey \& Kou, 2013), OC is a multilevel phenomenon, simultaneously encompassing individual, interpersonal (group) and organisational levels (Amabile, 1988; Drazin, Glynn, \& Kazanjan, 1999; Nisula, 2013; Woodman, Sawyer, \& Griffin, 1993). To stimulate OC, all these levels need to be covered.

How then can OC be fostered and supported? Most of the relevant literature has focused on techniques to improve creativity in specific and occasional creative events or problem-solving situations (Harvey, 2014). While useful in temporarily increasing creative productivity, the occasional application of such techniques as brainstorming (Osborn, 1953) or lateral thinking (DeBono, 1992) may not have much impact on employee creativity in day-to-day work. Furthermore, the main emphasis has been on improving idea generation (DeBono, 1992; Harvey \& Kou, 2013; Osborn, 1953; Paulus \& Brown, 2003). This perspective ignores the emergent nature of collective engagement in joint creation, where idea generation, implementation and problem definition all intertwine in a complex and iterative manner. There is a lack of knowledge about how to improve creativity as a quality that pervades everyday operations throughout an organisation.

If $\mathrm{OC}$ is understood not just as the production of novel ideas to respond to clearly defined specific problems, but rather as a holistic flexibility that allows to approach issues from new perspectives and an agile capability to grasp new opportunities, then its stimulation will benefit from techniques that help organisational actors to be in a state of continuous awareness, sensitivity and responsiveness. This differs from other OC approaches, which merely offer techniques for producing novel ideas to be utilised in clearly delineated special occasions. The necessity for a creativity-supporting culture of high performance is well recognised in innovation literature 
(Anderson \& West, 1998; West, 1990), and OC research has recently grown (Bissola \& Imperatori, 2011). Nonetheless, there is a need for studies to specifically examine how OC and the collective creative potential of organisational members can be built and stimulated.

This paper examines an arts-based approach as one potential to bridge the current knowledge gap in OC development. Arts-based approaches aim to utilise art processes and products (Taylor \& Ladkin, 2009) to support change and managerial development in organisations (Barry \& Meisiek, 2010; Schiuma, 2011). Specifically, we study how theatrical improvisation methods can be used to stimulate OC, a suitable strategy because improvisation is all about communication and interaction among the participants (Cunha \& Cunha, 2003; Kanter, 2002; Vera \& Crossan, 2005). As a creative performance - built through the interacting people's speech, gestures and movements - theatrical improvisation fosters both individual creativity (IC) and $\mathrm{CC}$, which are essentially intertwined. Empirically, we conducted action research (AR) involving three collective improvisation workshops with two groups of participants over a fivemonth period.

This study contributes to the OC literature and its development. First, it expands the understanding of $\mathrm{OC}$ as a phenomenon in which individual and collective creativity are essentially intertwined. Second, the study extends the OC literature by perceiving IC as consisting of both intrinsic and other-focused dimensions. Third, it adds to the literature on OC development by providing empirical evidence of the possibilities for theatrical improvisation to stimulate OC as a multilevel phenomenon. Fourth, the study enhances the emerging literature on arts-based methods and practices (Barry \& Meisiek, 2010; Schiuma, 2011; Taylor \& Carboni, 2008) by providing empirical evidence about using collective improvisation, drawn from improvisational theatre, to foster both IC and CC and thereby OC. The study's managerial contribution broadens the knowledge about practical methods to develop OC and to embed creativity into organisational members' daily work by showing the arts-based methods' potential for organisational development.

\section{Organisational creativity $(\mathrm{OC})$}

Researchers have adopted various perspectives on OC. The outcome view emphasises novel and useful products, processes, services and strategies (Amabile, 1996). The process view focuses on how creative outcomes are produced (Drazin et al., 1999; Fisher \& Amabile, 2009). Some scholars perceive OC as a creative organisational climate (Moultrie \& Young, 2009). In this study, we understand OC as an organisation's capacity to introduce novelty into what it does and how it does it in order to achieve organisational goals (including novel products, processes, services and paradigm shifts, as well as new ways to grasp opportunities, solve problems and face internal and external changes). In OC, both individual and collective (group and organisational) creativity are intertwined since there is no collective without individual contributions and interplaying individuals.

Individual creativity (IC) can be defined as the introduction of novelty into a person's knowledgeable actions (Nisula, 2013) or the introduction of the "unthought" into action (Hjort, 2005). It refers to an individual performing work in professional, creative and original ways. It is enabled by an individual seeing differently, exploring opportunities, drawing distinctions, making 
initiatives and converting knowledge and insights into action on behalf of individual, group or organisational goals (Oldham \& Cummings, 1996; Yuan \& Woodman, 2010).

Within IC, two aspects can be further isolated - intrinsic and other-focused. Intrinsic creativity stands for the individual's desire for imagination, passion, openness and creativity in one's personal thinking and behaviour. Someone with high intrinsic creativity is able to imagine and produce novel, useful outcomes based on one's personal ideas and intuitions (Csikszentmihalyi, 1996) and is intrinsically motivated to utilise one's expertise and creative thinking skills to generate new ideas (Amabile, 1988). This dimension of creativity is quite sufficient to understand people's creativity when working completely by themselves, but it does not account for an individual's role in collective and joint creative processes.

The second aspect of IC, other-focused creativity, denotes an individual's ability to work with and on the stimuli in a social setting. In any shared endeavour, a person's sensitivity to others and pro-social orientation are important dimensions of creativity in the individual domain. This aspect is crucial because creative activities in organisations tend to be more social than isolated ways of idea generation (Choi, Sung, \& Cho, 2014; Hammond, Neff, Farr, Schwall, \& Zhao, 2011). In fact, someone's pro-social creative contributions, such as expressing ideas, supporting others' initiatives and stimulating their creative energy (Choi et al., 2014), build joint creative processes. Thus, this vital aspect of IC involves other-focused orientation (Grant, 2008; Grant \& Berry, 2011; Neff \& Harter, 2003), which refers to someone's interest in interpersonal relationships, in others' needs (Neff \& Harter, 2003) and in benefiting them (Grant, 2008).

Collective creativity $(\mathrm{CC})$ is a process of joint creation, comprising the interdependent contributions of individuals, groups or entire organisations. Such creative synthesis emerges via interaction as a complex composition of participants' social and intellectual abilities. People's knowledge, imagination, ideas, creation of collective meaning, environmental influences, timing, luck and mistakes are all brought together into common creative achievements. Thus, $\mathrm{CC}$ highly relies on the interpersonal dynamics in situ. The participating individuals' contributions (Choi et al., 2014; Harvey, 2014; Harvey \& Kou, 2013), behaviours and interactions (John-Steiner, 2000) in this context also influence what is actualised (Woodman et al., 1993). Consequently, joint creation is enabled only if individuals contribute their attention and energy (Hargadon \& Bechky, 2006) to creative acts and fully engage in these (Drazin et al., 1999; Harvey \& Kou, 2013), while being willing to integrate others' contributions into the collective creation. Requiring specific circumstances, $\mathrm{CC}$ is likely to occur when the participating members work in an interdependent and egalitarian relationship, as well as when the task is challenging and its solution is open-ended, demanding a high level of creativity (Harvey, 2014; John-Steiner, 2000; Sawyer \& DeZutter, 2009).

\section{Theatrical improvisation and $\mathrm{OC}$}

Improvisation is defined as a spontaneous and intuition-guided action, as well as an unplanned and creative process to achieve a goal (Vera \& Crossan, 2004). It is linked to organisational change (Cunha \& Cunha, 2003; Orlikowski, 1996), learning (Miner, Bassoff, \& Moorman, 2001) and innovation (Vera \& Crossan, 2005; Moorman \& Miner, 1998). Improvisation and creativity are also perceived as parallel constructs (Miner et al., 2001). Frost and Yarrow (1989, p. 2), for 
example, argue that improvisation may be close to pure 'creativity'- or perhaps more accurately to creative organisation, the way in which we respond to and give shape to our world". Fisher and Amabile (2009) connect improvisation with creativity through the idea of improvisational creativity, where problem identification, idea generation and idea implementation happen simultaneously. In such creative behaviour, planning and action converge in the moment (Moorman \& Miner, 1998). Deviating from familiar practices and knowledge, improvisation radically builds space for new ones (Moorman \& Miner, 1998). Creativity and improvisation are thereby essentially intertwined.

Improvisational theatre is a collective activity in which a group of actors performs together - with no script or director - in a spirit of shared leadership, responsibility, mutual support and care. Planning and acting occur simultaneously in the moment (Johnstone, 1979; Moorman \& Miner, 1998; Weick, 1993; Yanow, 2001), and the events enacted determine the world of the performance, whereas the future is unknown (Weick, 1993). The actors draw from all possible sources for their contributions to the performance, applying their knowledge, imagination, intuitions, voices, experiences, along with the materials, tools and resources available at the moment (Johnstone, 1979). This can be described as the "free play of the resources" (Styhre \& Sundgren, 2009, p. 51) or bricolage (Levi-Strauss, 1966). The core of collective improvisation is the group acting in ensemble, which describes the collective flow of the unplanned performance, where the material enacted emerges from the group's intense interplay (Johnstone, 1979).

Similar to OC, theatrical improvisation includes both individual and collective levels (Table 1), yet in improvisation, these are understood as intertwined. Such an interactive process of creation strongly resembles the conditions of $\mathrm{OC}$, which is conducted in immediate social interaction and where reality is continuously and collectively (re)constructed. We argue that collective improvisation, as a unique process of co-creation, represents an emergent organisational and collective creative process. Training employees in theatrical improvisation can stimulate both IC and CC, leading to greater OC. Both CC and collective improvisation refer to dynamism - flexible capabilities relying on interconnectedness (Ciborra, 1996; Kellogg, Orlikowski, \& Yates, 2006), horizontal collaborations (Barley, 1996), relationships (Bechky, 2006) and the imperative to stay connected (Kellogg et al., 2006). These are vital for emergent co-creation (Harvey, 2014).

Next, we clarify our contributions and build a link between the dimensions of OC and the corresponding dimensions of theatrical improvisation.

First, cognitive, emotional and social openness are the sources of IC. The overwhelming barriers to creativity lie within individuals themselves (Johnstone, 1979; Kelley \& Kelley, 2012). Individuals may consider themselves non-creative and thus prefer to avoid situations demanding creativity rather than contribute to them. They may also be too self-critical, thus subduing their own thoughts or insights, or concerned about their own fear of failures or others' criticism, leading them to behave in an exceedingly rigid manner (Edmonson, 2008). However, individuals' senses, emotions, intuitions, passions and subjective experiences are the very drivers of creativity (Amabile, 1996; Chikszentmihalyi, 1996). This fact is clearly recognised in theatrical improvisation, and training therein aims to overcome individual obstacles by encouraging spontaneity and free expression (Johnstone, 1979). Thus, improvisation training can stimulate creativity by breaking down individual barriers and increasing individuals' and groups' openness to novelty. 


\begin{tabular}{|c|c|c|c|}
\hline \multirow[t]{2}{*}{ Dimension } & \multicolumn{2}{|l|}{ Creativity literature } & \multirow[t]{2}{*}{ Theatrical improvisation } \\
\hline & Construct & Authors & \\
\hline Individual intrinsic & $\begin{array}{l}\text { Creative desire } \\
\text { (emotions, imagination, } \\
\text { intuition, passion, } \\
\text { motivation) }\end{array}$ & Csikszentmihalyi (1996) & $\begin{array}{l}\text { Improviser open to imagine, } \\
\text { sense, feel, experience } \\
\text { (Johnstone, 1996; Koppett, } \\
\text { 2001) }\end{array}$ \\
\hline $\begin{array}{l}\text { Individual other- } \\
\text { focused }\end{array}$ & $\begin{array}{l}\text { Other-focused orientation: } \\
\text { sensitivity to others }\end{array}$ & $\begin{array}{l}\text { Neff and Harter (2003) } \\
\text { Grant (2008) } \\
\text { Grant and Berry (2011) }\end{array}$ & $\begin{array}{l}\text { Sensitivity to } \\
\text { others: listening and hearing } \\
\text { (Johnstone, 1996, Koppett, } \\
\text { 2001) }\end{array}$ \\
\hline Collective & $\begin{array}{l}\text { Collective creativity, } \\
\text { engagement in creative } \\
\text { acts, } \\
\text { Creative collectives, } \\
\text { co-creation, creative } \\
\text { synthesis } \\
\text { Creative climate }\end{array}$ & $\begin{array}{l}\text { Drazin et al. (1999) } \\
\text { Hargadon and Bechky } \\
\text { (2006) } \\
\text { Harvey (2014) } \\
\text { Sundgren et al. (2005) } \\
\text { Moultrie and Young } \\
\text { (2009) }\end{array}$ & $\begin{array}{l}\text { Group improvising and } \\
\text { acting in an ensemble } \\
\text { (Johnstone, 1996) } \\
\text { Collectively built climate for } \\
\text { improvisation (Johnstone, } \\
\text { 1996) }\end{array}$ \\
\hline
\end{tabular}

Second, an individual's other-focused orientation refers to one's level of consideration for others, as well as openness and willingness to contribute to others' initiatives and work for others. Interacting individuals who demonstrate mutual consideration can co-create a shared space for collective creation to emerge. In improvisational theatre, highly dynamic group interplay is enabled by individuals who are other-focused. Because improvised performance is unplanned, the actors need to sense, listen to and hear one another constantly in real time. Collective improvisation can thereby occur when the actors interact by trusting and caring for one another, listening to and hearing others, and building on others' initiations and contributions (Johnstone, 1979; Koppett, 2001).

Third, the collective creative process is non-linear, emergent and results from interactions among individuals, group dynamics and contextual aspects (Bissola \& Imperatori, 2011; Harvey, 2014). In theatrical improvisation, the play unfolds in the dynamic communication and interaction among individuals, where non-verbal communication also has meaning. The group processes such as shared responsibility, emerging leadership, and mutual support and care - are enacted in situ by the participating actors. Notably, in theatrical improvisation, the roles are self-determined and changing, which include leadership roles, taken or given to others according to the situation. These characteristics build the actors' commitment and engagement in joint creation. We argue all of these can benefit OC as well.

Finally, the climate and the space for collective improvisation are built in the interaction among the people involved, fostering a culture of joint engagement. In such a generative, collective process of creation, "the interaction among group members often becomes a more substantial source of creativity than the inner mental processes of one participating individual" 
(Sawyer \& DeZutter, 2009, p. 83). Such an interplay can produce positive and enjoyable experiences and feelings of competence, autonomy and enjoyment, which are all vital for people's engagement in collaborative creative activities (Bissola \& Imperatori, 2011). Theatrical improvisation is a concrete example of an emerging creative process, in contrast to a linear and managed type of a creative process. Therefore, it can contribute to OC. Collective improvisation is grounded by a constant co-orientation between the actors and the events, where the self, the others and the environment form a developing dynamic system, thereby making space for creativity to emerge.

\section{Method}

\subsection{Research context}

This AR study's context was a large Finnish municipality organisation of 6,000 employees, created in 2009 by merging six smaller municipalities into one. The municipality's leaders anticipated severe economic and structural challenges, requiring a more effective production of public services with decreased resources. This need prompted them to embark on a long-term (2.5 years), university-driven research-development project, which aimed to improve the organisation's capacity for renewal and to build an innovative organisational culture. The need for AR arose from the results of a broad employee survey, which identified several obstacles to organisational renewal, such as the failure to utilise employee ideas and to learn from experience, the lack of feedback mechanisms and questioning existing methods. The research team and the HR management of the organisation deemed that theatrical improvisation workshops might constitute a suitable approach to enhance creativity and thereby improve organisational renewal overall.

\subsection{Research procedure}

AR was selected as the research strategy for studying how improvisation training could stimulate $\mathrm{OC}$, because the research topic involved an unfolding series of actions over time, within a given organisation, that aimed to improve the workings of some aspects of its system (Coghlan \& Brannick, 2010). Grounded by a collaborative democratic partnership that regards organisations as socially co-constructed (Campell, 2000; Coghlan \& Brannick, 2010), AR provides learning experiences for the participants and embodies research in action. The researcher simultaneously works to actively influence the organisation and to contribute to science (Gummesson, 2000). Accordingly, over the course of this research, several developmental interventions were organised in the organization, and this paper's lead author acted as a facilitator, consultant and researcher. Next, we describe the research procedure.

\subsection{Training workshops}

For this study, the improvisation training workshops were based on improvisational theatre exercises that are widely known and used in improviser communities and improvisation training courses and well documented in the literature (Johnstone, 1979; Koppett, 2001). The key rationale of improvisation training concerns exercising spontaneity, interpersonal trust, accepting offers, 
listening to and hearing others in the moment of action, verbal and non-verbal communication and storytelling (Koppett, 2001), that is, abilities to act collectively.

A series of three creativity-stimulating workshops constituted both the AR process and the sites for data collection in this study. Workshop I (WSI) focused on the basics of individual improvisation to immerse participants in exercises, spontaneous self-expression and contributing to the emerging situations. Workshop II (WSII) concentrated on collective improvisation through interactions among the participants, enabling them to listen, hear, engage and contribute to the course of action. The purpose of Workshop III (WSIII) was to recall and summarise the exercises and the lessons learned from the previous workshops. Appendix 1 shows the workshops' contents (exercises).

The workshops built on one another to increasingly stimulate IC and CC over time. Each workshop started with warm-up exercises to create an atmosphere and a common space of attention. Special exercises followed, each lasting for 15-25 minutes. After each exercise, a short reflection session allowed the participants to express and share their emotions, insights, experiences and lessons learned. Figure 1 presents Coghlan and Brannick's (2010) AR cycle (construct, plan, act and evaluate), along with the corresponding events and the actors' roles.

Figure 1: Action research procedure, events and actors' roles

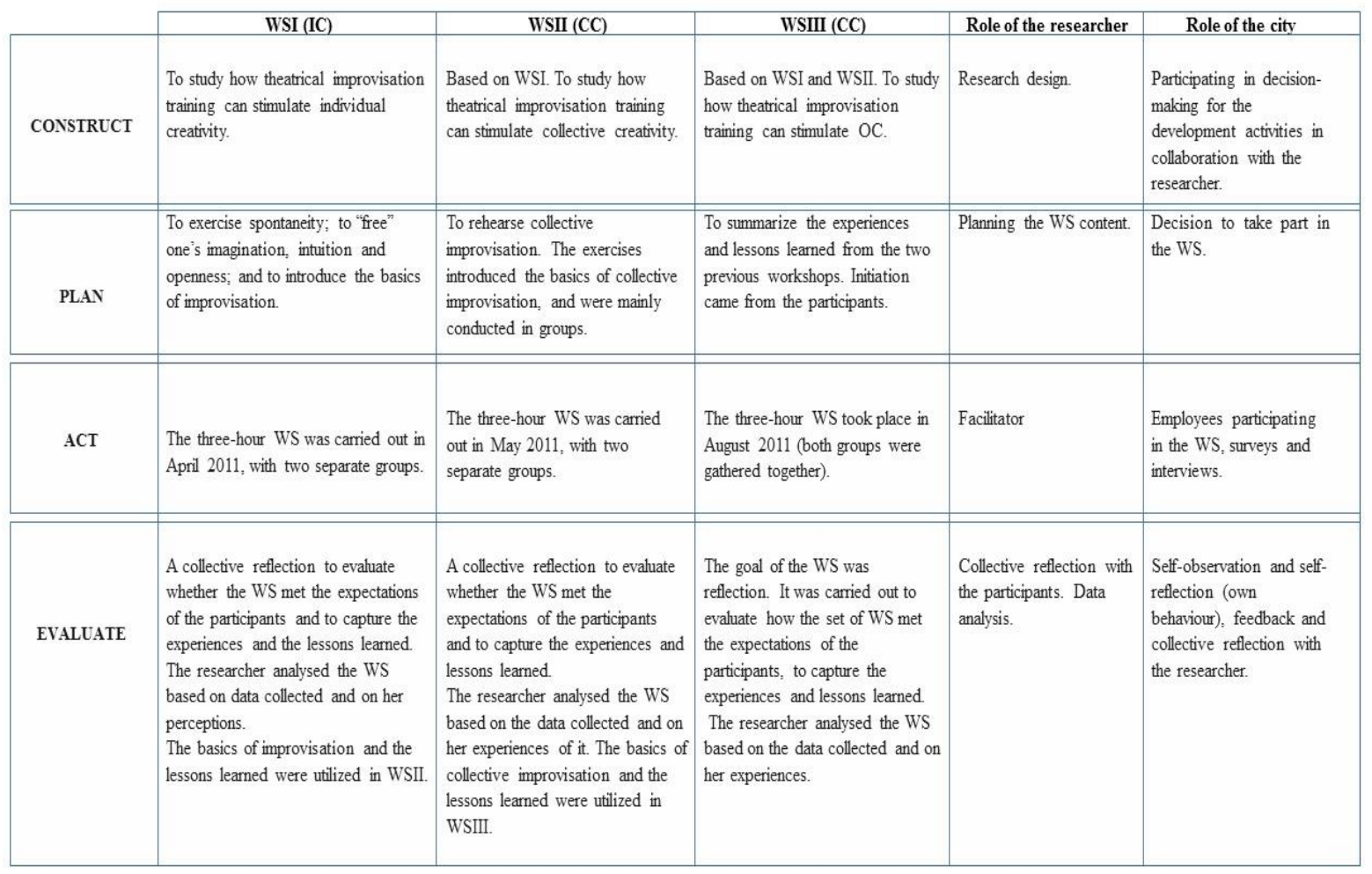

Note: $I C=$ individual creativity; $C C=$ collective creativity 


\subsection{Data collection and analysis}

The data were collected over a 20-month period (April 2011-November 2012); Figure 2 shows the timeline. The key AR activities and the data collection sites were the three creativity workshops, each lasting three hours and held with two separate groups. Each group attended nine hours of training in total. The participants were middle-level managers and experts. The Developers group (12 participants) mainly constituted experts and middle-level managers covering various sectors/units of the organisation. The Childcare group (six participants) all came from the same field of expertise and the same work unit.

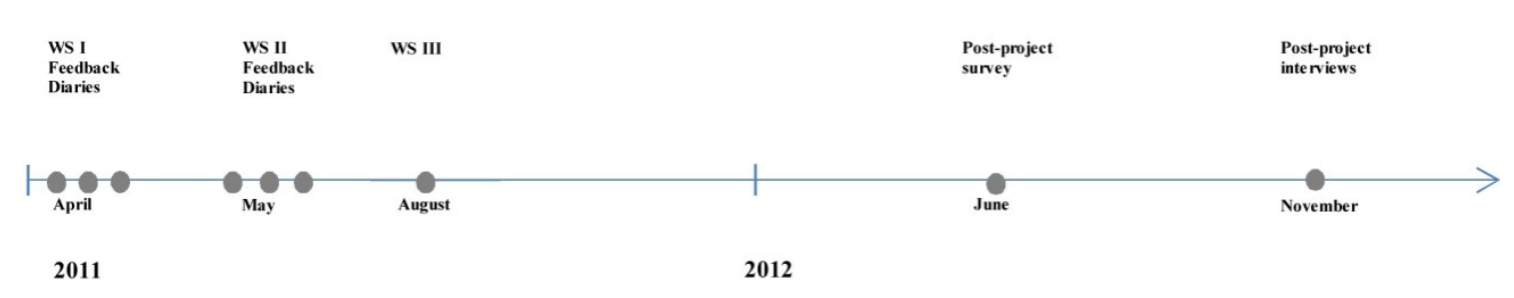

Figure 2: Timeline of data-collection events

Following AR principles (Coughlan \& Coghlan, 2002), multiple types of data were collected, including video and audio recordings, two workshop-feedback questionnaires, the participants' written diaries, a post-project survey and post-project interviews. The various data sources were considered appropriate for this study because we were interested in the participants' subjective experiences (Gummerson, 2000). Table 2 summarises the data sources, types and related analyses.

Videos: WSI and WSII were video-recorded and analysed by examining the participants' ability to immerse themselves in the exercises, their experiences and the atmosphere. First, we watched whether they participated and contributed voluntarily to the exercises. The facilitator informed them that participation was voluntary and that they could exclude themselves from an exercise if they felt like it. Second, we watched the participants' gestures. For example, smiling and laughing would show positive energy and playfulness. Third, we were interested in the workshops' general atmosphere, which was interpreted by observing the participants' interactions and spirit and listening to their communication.

Workshop-feedback surveys: After WSI and WSII, a short workshop-feedback survey was conducted. Five structured Likert-type items addressed the workshop content's importance for the respondent personally, as well as for his/her work and work community. The items were analysed by calculating their means. The four open questions asked to what extent the workshops met the participants' expectations and how they experienced the exercises, as well as requested for open feedback and development suggestions to improve the training. These were analysed through a content analysis procedure (Corbin \& Strauss, 2008). The table in Appendix II describes the categories in more detail. 
Table 2. Data collection and analyses

\begin{tabular}{|c|c|c|c|c|}
\hline Data source & Data type & $\begin{array}{l}\text { Participants } \\
\text { Responses/survey sent }\end{array}$ & Purpose & Analysis \\
\hline WSI & Video (5h.38min.) & 18 & \multirow{3}{*}{$\begin{array}{l}\text { To document the } \\
\text { workshop }\end{array}$} & \multirow{3}{*}{$\begin{array}{l}\text { Observe } \\
\text { participants' } \\
\text { engagement, } \\
\text { commitment, } \\
\text { experiences }\end{array}$} \\
\hline WSII & Video (5h.45min.) & 11 & & \\
\hline WSIII & Tape recording & & & \\
\hline WSI feedback & Likert scale items & $12 / 18$ & \multirow{2}{*}{$\begin{array}{l}\text { Participants' } \\
\text { perceptions }\end{array}$} & \multirow{2}{*}{$\begin{array}{l}\text { Statistical } \\
\text { analysis (means) }\end{array}$} \\
\hline WSII feedback & Likert scale items & $7 / 11$ & & \\
\hline $\begin{array}{l}\text { WSI\&WSII } \\
\text { feedback }\end{array}$ & Open questions & & $\begin{array}{l}\text { Participants' } \\
\text { experiences, } \\
\text { learning }\end{array}$ & \multirow{4}{*}{ Content analysis } \\
\hline Diaries & Written narratives & $8 / 18$ & Following learning & \\
\hline $\begin{array}{l}\text { Post-project } \\
\text { survey }\end{array}$ & Open questions & $11 / 40$ & $\begin{array}{l}\text { Influence of the } \\
\text { creativity } \\
\text { workshops }\end{array}$ & \\
\hline $\begin{array}{l}\text { Post-project } \\
\text { interviews }\end{array}$ & Theme interviews & $\begin{array}{l}1 \text { HR manager } \\
3 \text { interviewees } \\
\text { (participants of the } \\
\text { creativity } \\
\text { workshops) }\end{array}$ & $\begin{array}{l}\text { Long-term } \\
\text { influence of the } \\
\text { development } \\
\text { project }\end{array}$ & \\
\hline
\end{tabular}

Diaries: The participants were offered a voluntary opportunity to keep a diary after WSI and WSII, for the purpose of deepening and reflecting on the improvisation training and transferring it to the real-life context. After WSI, the participants were asked to choose one phenomenon introduced in the training (e.g., "Yes, and ..."), observe it in the context of their everyday work or free time for a few days and make related diary entries. After WSII, the participants were asked to describe the role of $\mathrm{CC}$ in their work and a situation when it had occurred. In addition to observation, the diary form included open questions, asking the respondents to report their thoughts and experiences about the exercises, the role of creativity in their work and how creativity was supported in the organisation. The diaries' themes adhered to the workshop themes (WSI - IC, WSII - CC). The diary data were analysed by content analysis (Appendix II).

Post-project data: The open questions in the post-project survey and the post-project interviews were partially used as data for this study. Conducted ten months after WSIII, the postproject survey inquired about the most significant consequences of the entire long-term development project; in this study, we involved only the questions related to the AR. The postproject interviews were conducted 15 months after WSIII with the HR manager and three middlelevel managers involved in the improvisation training. The interviews aimed to capture the entire project's long-term effects; one question asked about the creativity development workshops' influence on the organisation. The results are reported in the Findings section.

Content analysis was the major analysis method used for the interviews, the diaries and the open questions in the surveys. Following Corbin and Strauss' (2008) approach, we first performed an open-coding procedure. Similar types of codes (expressions) were then categorised into groups 
that formed the lower-level concepts (fun, foolery, play, playful, funny). These concepts were then categorised into themes (e.g., playfulness), describing what a group of lower-level concepts indicated. We chose manual coding due to the relatively small amount of data (Corbin $\&$ Strauss, 2008).

Following Denzin and Lincoln (1994), the data's richness and the researcher's experience enable interpretive research; the researcher is the bricoleur who constructs the study, relying on multiple data sources and one's experience and reflection. In this particular study, the lead researcher's theoretical background in OC and improvisation, as well as her experience as both an improviser and a facilitator of improvisation workshops, enabled the interpretive analysis. Thus, the study's findings are based on her understanding and synthesis.

\section{Findings}

This section presents the study's findings by discussing the improvisation workshops from the perspectives of IC and CC, along with the improvisation training's influence on OC.

\subsection{Individual creativity (IC)}

\subsubsection{Intrinsic dimensions of IC}

Our findings confirm that improvisation exercises can stimulate participants to behave differently from the way they do in everyday routines. Indeed, the exercises acted as habit breakers and eye openers and gave the participants new perspectives, arising thoughts and surprising insights (Appendix II). The exercises also broke conventional social rules, offering insights into the familiar thinking patterns and habits that limited the participants' openness to new ones. Thus, the improvisation exercises provided them with an opportunity to observe and rethink their own attitudes and behaviours, as demonstrated by the following quotes:

"It was an eye opener in many respects" (Feedback/WSI).

"I found the workshop fruitful because, instead of talking, we concentrated on doing and experiencing things. A change can only take place by reprogramming one's mind, and it is only possible by doing things differently, for example, through play, by experiencing things. The workshop offered an opportunity to gain experiences" (Feedback/WSI).

"After the initial shyness and awkwardness, the exercise felt meaningful. I understood the significance 'letting go' can have” (DiaryI/Respondent5).

Via improvisation training, the participants recognised themselves in a new light and came to value their tacit abilities:

"I found my strong self-confidence" (DiaryI/Respondent4).

"We miss a lot of things when we don't 'listen' to our inner consciousness; we don't pay attention to our intuition but think of it as nonsense" (Feedback/WSII).

In sum, the findings show that playful and positively surprising exercises, which radically differ from habitual ways of behaving, can release individuals from familiar settings and enable more 
creative actions to occur. Overall, the training helped overcome individual barriers to creativity by enabling the participants to express their spontaneous creative insights and be less concerned about self-criticism. An opportunity to experience in practice is effective and can trigger learning, as expressed by a respondent: "We experienced in practice, how an idea starts to flow, when another person is inspired and thereby inspires me [...]" (DiaryI/Respondent3). This is important because creativity cannot be taught but is rather awakened and enabled (Johnstone, 1979; Kelly \& Kelly, 2012; Styhre \& Sundgren, 2009). Thus, improvisation training seems to serve as an eye opener and is thereby a promising method to stimulate individual intrinsic creativity and confidence in one's ability to be creative.

\subsubsection{Other-focused dimension of IC}

Our findings reveal that experiencing, in practice, two opposite verbal approaches (agreeing or "Yes, and ..." versus disagreeing or "Yes, but ...") to contribute to interaction is an effective pattern breaker through which the participants can observe and rethink their own behaviour. The respondents discovered that "Yes, but ..." inhibited interactions, initiations and idea generation, as the following quote illustrates:

"Yes, but... is a depressing way to react to this, and someone may only say it so that he or she wouldn't have to do anything" (DiaryI/Respondent2).

In contrast, positive communication was found to stimulate and lead to novel ideas. One respondent consciously decided to use the positive wording 'Yes, and ...' in her work, during her (diary) observation period. The quote below describes her insights:

"The other party in the conversation gets excited and develops his or her idea, notices new perspectives on it and the idea develops. It creates a genuine feeling of interaction and its fruitfulness" (DiaryI/Respondent3).

Another respondent observed the influence of positive wording on communication with her friends, describing it as follows:

“When you use 'yes, and...' a lot, nice things tend to happen. You do fun stuff with friends. I noticed my friends are pretty much the 'yes, and'-type, and there is a lot of talk to cheer up other people. Not once did I have one of my ideas shot down" (DiaryI/Respondent1).

The participants also learned to consciously pay attention and improve their own behaviour when interacting with others. The following quotes are examples:

"It's all too easy to slip out that it can't be/go like that, even when it's someone else's turn to speak. I'm embarrassed now. I will learn how to listen until the end, even if it's something stupid" (DiaryI/Respondent3).

"I recognised a strong "yes-but" attitude in my behaviour, which I have tried after the workshop to consciously inhibit, and instead I encourage others to develop their ideas. I hope I manage to improve my interaction skills in this sense" (Diary/Respondent3).

In sum, our findings show that improvisation training - and its experience in practice awakens individuals' consciousness about how the quality of communication contributes to interaction and creativity. Other-focused individuals engage in interaction and fuel it through 
positive communication. The positive wording indicates that the other's initiation is heard, recognised and agreed on, thereby fuelling interaction and accelerating idea development and creativity. Thus, improvisation training can stimulate the other-focused dimension of creativity by 1) making visible an individual's role and responsibility when considering others and their ideas and 2) highlighting the quality of communication and interaction that can foster joint creation. Anyone can make the choice to consider others and direct an interaction towards a supportive instead of a negative cycle, thereby building a basis for OC.

\subsection{Collective creativity $(C C)$}

We found that through improvisation exercises, the participants discovered the importance of consciously built social cohesion and atmosphere to create space for group interaction. For instance, one respondent stated:

"Through the concepts and methods of creativity, it is possible to improve the social cohesion of the work community and, thereby, find new solutions and improve the efficiency of each person's work" (Diary/Respondent1/WSI).

Through improvisation training, the participants experienced in practice the antecedents of $\mathrm{CC}$, such as intense attention and engagement, sensitivity to others, listening and hearing, and contributing. This experience led them to recognise the disabling issues around $\mathrm{CC}$ in their own work community, as described by a respondent:

"The session of collective creativity emphasised taking others into account and listening, genuinely being there. Everyone took part in the exercises, but the quieter ones in the work community easily stayed on the bench. The more prominent personalities easily steamroll others and the quieter ones don't dare or bother to say anything" (Diary/Respondent3/WSII).

The participants realised their own possibilities and responsibilities in contributing to and performing actions for collective creation. Such CC depends on each individual's active engagement, energy and motivation, as well as courage to take action, make different choices and contribute to situations. The following quote describes this specifically:

"I understood once again how little things lead to change and that change in a community always starts from individuals. We often seek flamboyant visions and models and draft process descriptions, but we tend to forget how learning or change occurs in the individual and how small things can support it" (Feedback/WSI).

The exercises fruitfully modelled collective creation in practice. In the story-telling exercise, the participants told a story together, turn by turn, one word at a time. The story's future was open-ended, and the storyline evolved according to the words expressed and the meanings given by the actors. Each participant had an equal possibility to contribute to the narrative, but anyone could build one's own story or control its events. Each contribution depended on the immediately preceding one and was interpreted by the following participants. All these aspects characterise CC and the creative process (Sawyer \& DeZutter, 2009).

In sum, the findings show that improvisational theatre training can stimulate $\mathrm{CC}$ by 1) making visible the individual antecedents (intense attention, listening to and hearing others) and 
interaction-related antecedents (mutual support and care, shared responsibility and leadership) of the collective creative process, 2) making visible the importance of individual contributions (taking ownership and engagement) to collective creation, 3) building the ensemble (i.e., space and climate for creativity) and 4) demonstrating in practice the collective creative process, thereby providing the participants with joint creation experiences.

\subsection{Influence of theatrical improvisation workshops}

We found several areas where the arts-based AR we conducted influenced the municipality organisation. The participants considered the exercises useful and beneficial for themselves personally, as exemplified by the following quote:

"I expected Power Point presentations, but in fact, I got much more! My eyes were opened in many senses" (Feedback/WSI).

The participants also considered the workshops useful for their work community, increasing their sense of community and cross-unit interaction, as described in the following quotes:

"Workshop increased sense of community. In a large organisation people work in silos, and these kinds of workshops help in feeling broader sense of community" (Feedback/WII).

"It was nice to discuss and get to know people from the other work units, and to get new perspectives for the development of the work. These kinds of events and workshops would work well in development of work communities" (Diary II/Respondent3).

Nevertheless, in a contradictory finding, one respondent reported in her diary and feedback that she did not understand the meaning of the exercises. She became involved in the improvisation training after WSI, where the basics of improvisation were introduced, and probably did not embrace the social atmosphere already built in the group or the key ideas of improvisation. Altogether, the respondents considered the workshops important, with a mean score of 3.9 each (scale of 1-5). The score was based on three items: the importance of the workshop's content for the respondent personally, for his/her work and for the work community.

The training directly influenced the methods applied in at least one working unit. The workshop experiences encouraged an actor to apply a concrete novel suggestion in her work community, as she described:

"After the first [IC] workshop, I suggested to him [the supervisor] that we could start introducing alternative elements into our team meetings, and he welcomed the idea. Already in the next meeting we first visited an art exhibition after which we held a meeting without an agenda and yet discussed a lot of things that the members brought up" (Diary/Respondent2/WSI).

Regarding the improvisation workshops' long-term effects, the analysis of the post-project survey showed that the training influenced the respondents' personal attitudes by increasing their awareness and making visible their own role in initiating change. In the post-project interviews, an informant reported her intention to promote creativity methods in her work unit in the near future so as to initiate customer-oriented collaborative practices. Another interviewee considered the training highly valuable personally but recognised that the new behaviours would reach their 
full potential only when many individuals from the same work community would be involved in the training:

"It would have been nice, in terms of communal learning, to put together a group of people who work together continuously. It would be nice to continue the discussion in the work team and draw the maximum advantage out of the experience. Now I am afraid that the experience will remain detached" (Post-project Interviewee 2).

Overall, the results show that the theatrical improvisation training was useful, eye opening and inspiring for both the participants and their work community. The participants started to introduce new practices and change either their own work or their work community.

\section{Conclusions}

In response to the growing interest in the development of $\mathrm{OC}$, we have explored the theatrical improvisation-based training to stimulate creativity as a multilevel phenomenon. Our findings indicate that improvisation training can act as a pattern breaker and an eye opener, thus both releasing and stimulating an individual's intrinsic creativity. The spontaneous and surprising interactions that emerge from improvisation leave no room for individuals' self-criticism. Instead, they have to respond immediately to contribute to joint creation. The improvisation exercises also lead to the participants' self-discovery by recognising themselves in a new light. These findings align with a similar key proposition from the theatrical improvisation perspective, which additionally assumes that the participants can consciously change their behaviour if they want (Johnstone, 1979; Koppet, 2001). Our results confirm that this outcome can happen in more traditional organisational settings, too.

Individuals' other-focused orientation is also a critical aspect of OC because in work settings, novelty creation is more about joint activities than idea generation in isolation. Our study highlights this fact and reveals that theatrical improvisation training can stimulate other-focused creativity. This facet of IC is much utilised in improvisational theatre and reported in related literature (Johnstone, 1979; Koppett, 2001) yet has remained a neglected issue in creativity studies.

Our findings are important since methods of and studies on fostering CC are still rare (Harvey, 2014). Per our findings, experimentation in practice is an effective pattern breaker, through which participants can observe and learn about CC. The participants discovered each individual's role in the CC process, which can feed creativity in their own work and work community. Through co-experiencing, sharing experiences and linking their experiences to their actual work, the participants could perceive their work community differently. We contribute to the CC literature by extending previous studies' findings (Sawyer \& DeZutter, 2009; Vera \& Crossan, 2005), as well as to the literature on theatrical improvisation (Johnstone, 1979; Koppett, 2001) by providing empirical evidence of the utilisation of theatrical methods in organisational development.

Our empirical evidence demonstrates that theatrical improvisation training can lead to sustainable changes at many levels of an organisation. After the workshops, some participants became encouraged to make novel suggestions to change their work community's habitual 
practices. This shows that their learning began to transfer to the broader organisation. Some middle-level managers intended to apply this creativity-stimulating approach in their work in the near future. These results indicate the training's influence on the work community, which can be determined by evaluating how the new practices or the lessons learned become part of the organisational work life or change the communication, interaction, leadership practices and quality of the work life (Franco-Santos, Lucianetti, \& Bourne, 2012).

The study provides novelty by introducing a multilevel view of understanding and stimulating OC. Addressing individuals and the collective (groups of individuals), theatrical improvisation-based method stimulates both as essentially intertwined phenomena. The perspective is vital to fostering OC, which is enabled by interacting individuals, and is possible only if they are able to openly shift their attention to others and stay actively focused on them (Yanow, 2001). The power of theatrical improvisation training is that as a pattern breaker and an eye opener, it provides opportunities for participants to observe habitual patterns and related limitations and to shift their focus if they wish. Consequently, we argue that theatrical improvisation-based methods can constitute a viable way to advance OC and develop collective capabilities.

The study provides an amended understanding of IC as comprising intrinsic and otherfocused dimensions. Intrinsic IC relates to the conventional interpretation, that is, the creative abilities of individuals who produce novel and useful ideas by themselves. The other-focused aspect of IC highlights the social nature of creativity by addressing individuals' abilities to participate in and contribute to shared acts of creation. Ultimately, this means broadening the knowledge about IC from the archetype of the lone genius operating in a vacuum to a more social understanding of the individual basis of creativity. It thus extends Csikszentmihalyi's (1996) seminal work on intrapersonal creativity.

The study contributes to the literature on the arts-based methods (Meisiek \& Barry, 2007; Schiuma, 2011; Taylor \& Carboni, 2008) by introducing an arts-based approach to fostering OC and providing empirical evidence of its implementation in the context of a public organisation. Furthermore, the study enhances the discussion about the value of arts-based initiatives in organisations (Garluzzi \& Schiuma, 2015) by presenting empirical evidence of the benefits and the influence of theatrical methods in order to develop the creative and collective potential of human resources, thereby achieving stronger collective capabilities and increasing OC.

What can practising managers, wanting to improve their organisations' creativity, learn from this study? First, creativity comes in many shapes and sizes and can be found across the organisation. Novel ideas can be and are ideally produced and applied throughout the organisation, with each employee having the potential to contribute to renewing the organisation and increasing its innovativeness. This means that creativity can be found and developed in all employee groups, regardless of job description or status. Second, while traditional creativity techniques, such as brainstorming and lateral thinking, may be useful for improving creativity in clearly defined problem-solving situations, improving an organisation's overall creativity is a much broader issue that hinges on developing the workplace culture and the activities facing employees daily. Third, an organisation's overall creativity is built through both individual and collective abilities and activities; to improve creativity, both levels should be addressed. Individuals' intrinsic creativity (the will, ability and desire to develop new ideas) is a significant issue. Moreover, the ability to tune in to others in social situations (other-focused creativity), which involves attending to social 
cues and being responsive to others in the moment, is equally important. Finally, it is vital to have people work together in a creative constellation to produce truly shared creative products since most work is a joint effort. Our findings show that all levels of creativity can be supported by building situations where individuals are willing and able to use their capacities to react effectively to surprising stimuli, in the flow of the moment and in a socially supportive and playful atmosphere. In sum, supporting creativity is not so much about having employees who are full of new ideas; more importantly, it entails creating a social work environment where people who perhaps never previously thought of themselves as creative are now empowered to use their creative abilities. These skills can then be applied to developing new ideas themselves, as well as boosting and energising others to do so. Ideally, they will also contribute to the co-creation process. According to our study, theatrical improvisation provides an excellent method for building such a work environment.

This study also has certain limitations. Its goal has been to explore the possibilities for using collective improvisation to stimulate OC. Despite the promising findings in this case, the investigation needs to be repeated in other cases and contexts to generalise the results. Stimulating creativity is a highly human and context-dependent issue. It is important to examine under what conditions such a facilitation method is possible and how it should be adjusted to match the contextual requirements of each social system to be developed. Acknowledging these drawbacks, we argue that collective improvisation training is a method with the potential to stimulate OC. Furthermore, in future studies, its effect should also be measured with quantitative methods.

Overall, this study adds to the knowledge about OC by suggesting that building it is fundamentally based on simultaneously fostering IC and CC. Such capabilities are increasingly crucial to fostering flexible and agile organisations, to the extent that OC may very well be a key competitive advantage in the contemporary economy.

\section{References}

Amabile, T. M. (1988). A Model of creativity and innovation in organisations. In B. M. Staw and L. L. Cummings (Eds.), Research in organisational behavior (pp. 123-167). Greenwich, CT: JAI Press.

Amabile, T. M. (1996). Creativity in context. Boulder, CO: Westview Press.

Barry, D., \& Meisiek, S. (2010). Seeing more and seeing differently: Sense making, mindfulness, and the workarts. Organisation Studies, 31(11), 1505-153.

Bechky, B. A. (2006). Gaffers, Gofers, and Grips: Role-Based coordination in temporary organisations. Organisation Science, 17(1), 3-21.

Bissola, R., \& Imperatori, B. (2011). Organising individual and collective creativity: Flying in the face of creativity clichés. Creativity and Innovation Management, 20(2), 77-89.

Campell, D. (2000). The Socially Constructed Organisation. Bristol: Policy.

Ciborra, C. U. (1996). The platform organization: Recombining strategies, structures, and surprises. Organization science, 7(2), 103-118.

Choi, J. N., Sung, S. Y., \& Cho, T. S. (2014). Creative contribution of individuals in groups: Effects of goal orientation and participative safety. Social Behavior and Personality: An International Journal, 42(3), 407-422. 
Coghlan, D. and Brannick, T. (2010). Doing action research in your own organisation. $3^{\text {rd }}$ edition. UK, SAGE Publications.

Corbin, J., \& Strauss, A. (2014). Basics of qualitative research: Techniques and procedures for developing grounded theory. : SAGE Publications.

Coughlan, P., and Coghlan, D. (2002). Action research for operations management, International Journal of Operations and Production Management, 22, 220-240.

Denzin, N. L., \& Lincoln, Y. Y. (1994). Handbook of Qualitative Research, Sage Publications, Inc., USA

Catmull, E. (2008). How Pixar fosters collective creativity. Harvard Business Review, September, 2008, 1-13.

Csikzentmihalyi, M. (1996). Creativity. Flow and the psychology of discovery and invention. USA: New York, Harper Perennial.

Drazin, R., Glynn, M.A., and Kazanjan, R. (1999). Multilevel theorizing about creativity in organisations: A Sensemaking perspective. Academy of Management Review, 24(2), 286-307.

Fisher, C. M. and Amabile, T. (2009). Creativity, improvisation and organizations. The Routledge companion to creativity, 13-24.

Franco-Santos, M., Lucianetti, L., \& Bourne, M. (2012). Contemporary performance measurement systems: A Review of their consequences and a framework for research. Management Accounting Research, 23(2), 79-119.

Frost, A. and Yarrow, R (1989). Improvisation in Drama. USA: New York, St. Martin's Press.

Garlucci, D. and Schiuma, G. (2015). Capturing and assessing the value of the arts based initiatives in organisation. Proceedings of the $10^{\text {th }}$ Conference of International Forum of Knowledge Assets Dynamics (IFKAD), Culture, Innovation and Entrepreneurship: connecting the knowledge dots. Bari, Italy, 10 - 12 June 2015.

Gummesson, E. (2000). Qualitative Methods in Management Research, $2^{\text {nd }}$ ed. Thousand Oaks, CA: SAGE Publications.

Grant, A. M. (2008). Does intrinsic motivation fuel the prosocial fire? Motivational synergy in predicting persistence, performance, and productivity. Journal of applied psychology, 93(1), 48.

Grant, A. M. and Berry, J. W. (2011). The Necessity of others is the mother of invention: Intrinsic and prosocial motivations, perspective taking, and creativity. Academy of Management Journal, 54(1) 73-96.

Hammond, M. M., Neff, N. L., Farr, J. L., Schwall, A. R., \& Zhao, X. (2011). Predictors of individual-level innovation at work: A Meta-analysis. Psychology of Aesthetics, Creativity, and the Arts, 5(1), 90.

Hargadon, A. B. and Bechky, B. A. (2006). When Collections of creatives become creative collectives: A Field study of problem solving at work. Organisation Science, 17, 484-502

Harvey, S. (2014). Creative synthesis: Exploring the process of extraordinary group creativity. Academy of Management Review, 39(3), 324-343.

Harvey, S., \& Kou, C. Y. (2013). Collective engagement in creative tasks: The role of evaluation in the creative process in groups. Administrative Science Quarterly, 58(3), 346-386.

Johnstone, K. (1979). Impro: Improvisation and the Theatre. UK, Faber and Faber Ltd.

Kelley, T. and Kelley, D. (2012). Reclaim Your Creative Confidence. Harvard Business Review 
South Asia. 111-114.

Kellogg, K. C., Orlikowski, W. J., \& Yates, J. (2006). Life in the trading zone: Structuring coordination across boundaries in postbureaucratic organizations. Organization science, 17(1), $22-44$

Koppet, K. (2001). Training to imagine. Practical improvisational theatre techniques to enhance creativity, teamwork, leadership, and learning, LLC, CA: Stylus Publishing.

Levi-Strauss, C. (1966). The savage mind. University of Chicago Press.

Miner, A. S., Bassoff, P., and Moorman, C. (2001). Organisational improvisation and learning: A Field study. Administrative Science Quarterly, 46, 304-337.

Moultrie, J., \& Young, A. (2009). Exploratory study of organizational creativity in creative organizations. Creativity and Innovation Management, 18(4), 299-314.

Moorman, C. and Miner, A. S. (1998). The Convergence of planning and execution: Improvisation in new product development. Journal of Marketing, 62, 1-20.

Neff, K. D., \& Harter, S. (2003). Relationship styles of self-focused autonomy, other-focused connectedness, and mutuality across multiple relationship contexts. Journal of Social and Personal Relationships, 20(1), 81-99.

Nisula, A. M. (2013). Building OC - A Multitheory and multilevel approach for understanding and stimulating OC. Acta Universitatis Lappeenrantaensis.

Oldham, G. R. and Cummings, A. (1996). Employee creativity: Personal and contextual factors at work. Academy of Management Journal, 39(3), 607-634.

Osborn, A. F. (1953). Applied imagination.

Sawyer, R. K. and DeZutter, S. (2009). Distributed creativity: How Collective creations emerge from collaboration. Psychology of Aesthetics, Creativity, and the Arts, 3, May, 81-92.

Styhre, A. and Sundgren, M. (2005). Managing creativity in organisations: Critique and practices. Basingstoke: Palgrave Macmillan.

Schiuma, G. (2011). The Value of arts for business. Cambridge University Press.

Taylor, S. S., \& Ladkin, D. (2009). Understanding arts-based methods in managerial development. Academy of Management Learning \& Education, 8(1), 55-69.

Weick, K. E. (1993). Organisational redesign as improvisation. In: G. P. Huber and W. H. Click, (Eds.). Organisational change and redesign. Ideas and insights for improving performance (346-379). Oxford University Press.

Vera, D. and Crossan, M. (2005). Improvisation and innovative performance in teams. Organisation Science. 16, 203-224.

Woodman, R. W., Sawyer, J. E., and Griffin, R. W. (1993). Toward a theory of OC. Academy of Management Review, 18, 293-321.

Woodman, R. W. (2009). Creativity and organisational change: Linking ideas and extending theory. In: J. Zhou, and C. E. Shalley, (Eds.), Handbook of OC. 283-302. New York: Psychology Press, Taylor and Francis Group.

Yanow, D. (2001). Learning in and from improvising: Lessons from theatre for organisational learning. Reflections, 2(4), 58-65).

Yuan, F. and Woodman, R. W. (2010). Innovative behaviour in the workplace: The role of performance and image outcome expectations. Academy of Management Journal, 53, 323-342. 
Zhou, J., \& Hoever, I. J. (2014). Research on workplace creativity: A review and redirection. Annu. Rev. Organ. Psychol. Organ. Behav., 1(1), 333-359.

Anna-Maija Nisula, D.Sc. (Econ. \& Bus. Adm.), is Post-doctoral researcher at the LUT School of Business and Management at Lappeenranta University of Technology. Her work has been published in the International Journal of Human Resource Management, Leadership and Organization Development Journal, Creativity and Innovation Management and Interdisciplinary Journal of Information, Knowledge and Management. Her research focus is on knowledge management, organisational creativity, organisational learning and creativity.

Aino Kianto,D.Sc. (Econ. \& Bus. Adm.) is a Professor of Knowledge Management at theSchool of Business and Management at Lappeenranta University of Technology (LUT), and the Academic Director of the Master's Program in Knowledge Management and Leadership. Her teaching and research focus on Knowledge Management, Intellectual Capital, Creativity, Innovation and Organisational Renewal. She has authored and co-authored more than 100 academic articles, papers, books and book chapters on these topics.

APPENDIX I: Exercises in the workshops

\begin{tabular}{|c|c|c|c|c|c|}
\hline WSI & $*)$ & Form & WSII & $*)$ & Form \\
\hline Nonsense naming & 1 & Individual & Tell something about yourself & 1 & \multirow{10}{*}{ Group } \\
\hline $\begin{array}{l}\text { "Travelling" and telling a story } \\
\text { together one word at time }\end{array}$ & 3 & \multirow[t]{3}{*}{ Pair } & Ball toss & 2 & \\
\hline Disagree /agree an offer & 1,2 & & $\begin{array}{l}\text { Ball ball (several balls) - } \\
\text { movement }\end{array}$ & 1,2 & \\
\hline Accept and add & 1,2 & & Group counting & 2 & \\
\hline Yes, but...vs. Yes, and... & 1,2 & Two groups & Group jumping & 2 & \\
\hline Celebrate failure & 2 & \multirow{5}{*}{ Group } & Name story exchange & 2 & \\
\hline Get to know each other's names & 3 & & Conducted narrative & 2 & \\
\hline $\begin{array}{l}\text { Invisible balls with words - } \\
\text { movement }\end{array}$ & 3 & & One-word-at-a-time & 2 & \\
\hline Status cards & 3 & & Speaking in unison & 3 & \\
\hline \multirow[t]{2}{*}{ Telling a story one word at time } & 1,2 & & $\begin{array}{l}\text { Telling a story one word at } \\
\text { time }\end{array}$ & 2,3 & \\
\hline & & & Grouping by interest & 3 & $\begin{array}{l}\text { Two } \\
\text { groups }\end{array}$ \\
\hline
\end{tabular}

*) Source: 1) Johnstone, 1979; 2) Koppett, 2001; 3) Training course 
APPENDIX II: Coding and concept development of qualitative data

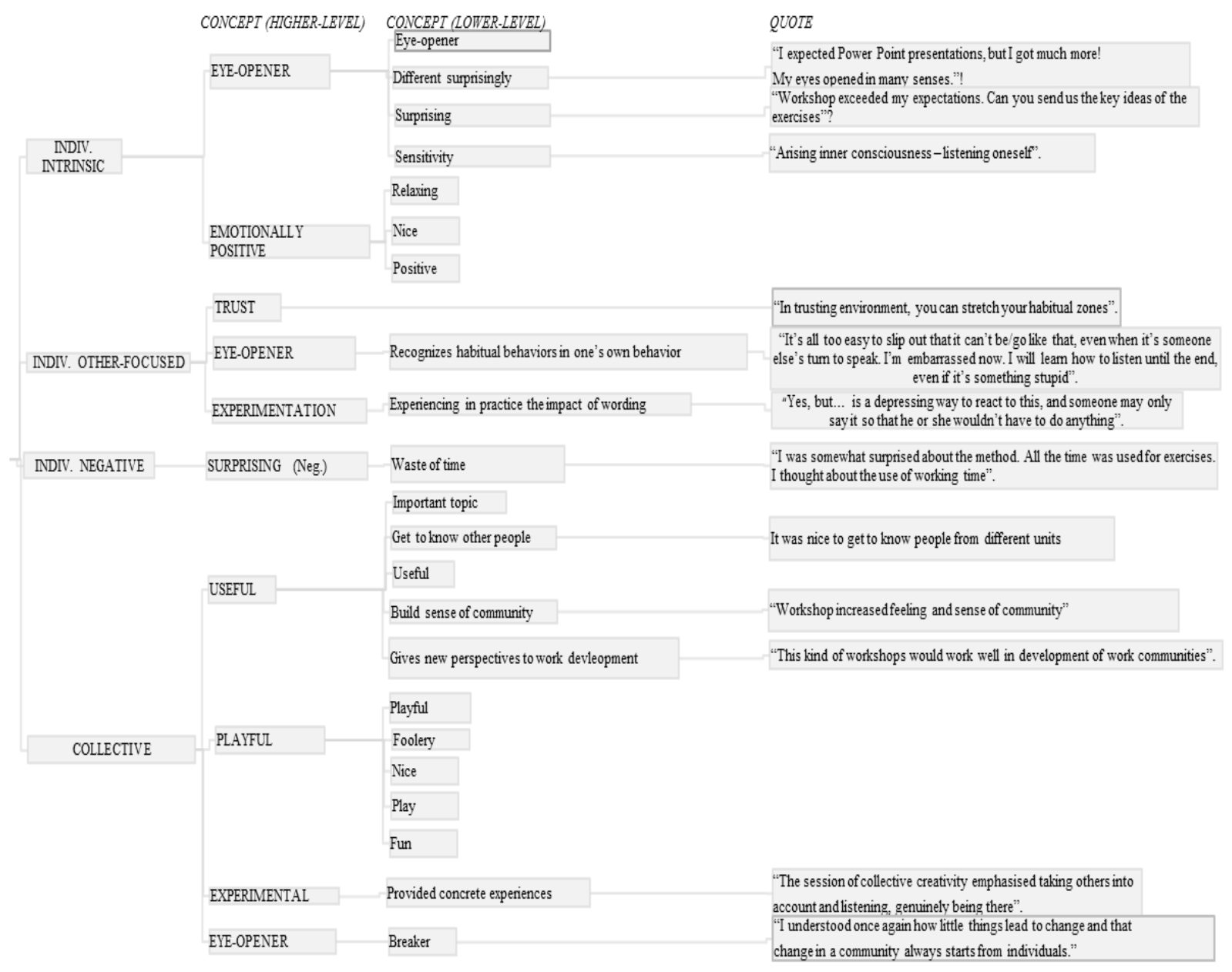

